\title{
LA CASTELLANIZACIÓN Y NEGACIÓN DE LA LENGUA MATERNA EN LA ESCUELA INTERCULTURAL EN CHIAPAS
}

\author{
Óscar Cruz Pérez
}

Resumen: El trabajo es producto de una investigación cualitativa más amplia sobre el ejercicio del poder en el acto pedagógico en escuelas interculturales bilingües de educación primaria en comunidades indígenas de los municipios de Ocozocoautla y Berriozábal en el estado de Chiapas. Es un acercamiento a la realidad de las prácticas pedagógicas a través del estudio de caso. Los datos empíricos muestran que en la operatividad del acto pedagógico subyace una concepción conservadora de la sociedad, pues la tarea central es integrar al alumno indígena a la cultura hegemónica a través del ejercicio del poder y dominación, ya sea negando su lengua materna, modelando los cuerpos, castigando las formas de resistencia y desvalorando la identidad propia.

Palabras claves: Acto pedagógico, educación intercultural, lengua materna, castellanización y poder.

Enviado a dictamen: 04 de abril de 2011

Aprobación: 23 de septiembre

Revisiones: 1

Dr. Oscar Cruz Pérez, doctor en Ciencias Sociales y Humanísticas por el Centro de Estudios Superiores de México y Centroamérica (CESMECA). Labora en la Facultad de Ciencias Humanas de la UNICACH. Temas de especialidad: procesos sociales y educativos, salud laboral. Correo electrónico: cruzperez25@hotmail.com.
Abstract: The work is a product of a wider qualitative research on the exercise of power in the act of teaching in intercultural bilingual primary schools in indigenous communities of the municipalities Ocozocoautla and Berriozábal in the state of Chiapas. It is an approach to the reality of teaching practices through a study case. Empirical data show that in the operation of the teaching act behind a conservative society, as the central task is to integrate indigenous students to the cultural hegemony through power and domination, denying either their mother tongue, modeling bodies, punishing devalued forms of resistance and self-identity.

Keywords: Teaching Act, intercultural education, mother tangue, castilianization and power.

\section{Sobre la educación intercultural}

$\mathrm{L}$ a educación intercultural está nutrida de una serie de promesas, de discursos políticos y buenas intenciones que en la práctica educativa y pedagógica no se cumplen. Desde su instrumentación en México y concretamente en Chiapas, tiene una concepción reduccionista, dirigida exclusivamente a las poblaciones indígenas. En Europa, por ejemplo, el discurso multicultural e intercultural respecto a la protección de las minorías y al reconocimiento de 
derechos colectivos surge a partir de la estabilización económica y de las migraciones producidas en décadas anteriores (Marí, 2007: 66 y 67).

La educación intercultural no es una escuela exclusiva para poblaciones indígenas, sino para atender a la diversidad de identidades sociales, múltiples y diferentes y con posiciones sociales de exclusión y discriminación (económicas, culturales, de género, preferencias sexuales, diferencias raciales, discapacitados), productos de un proceso globalizador y del cuestionamiento de la identidad de los grupos sociales en todo el mundo, por la tendencia a la promoción de una cultura hegemónica occidentalizada.

La educación intercultural contradice la falsa creencia que se tiene en muchos países del mundo, incluido el nuestro, de que se trata de una propuesta o de un tipo de educación construida para atender las necesidades educativas de las minorías sociales y de los pueblos indígenas (León, Trujillo, 2008: 65).

Su propuesta rebasa la condición indígena y se instala como una alternativa de inclusión, de diálogo y de equidad entre grupos sociales diferentes, con la intención de proponer formas más humanas de convivencia y estilos de vida.

Si bien es cierto que la educación intercultural no es exclusiva para las poblaciones originarias, en México, sin embargo, cuando se hace referencia a ella, se piensa en los indígenas, en poblaciones que poseen una lengua diferente al castellano, que utilizan una vestimenta autóctona y que están en condiciones de vulnerabilidad. Esta representación colectiva va definiendo la forma y el modelo de atención educativa a este tipo de población.

Para Dietz (2009) los avances de la educación intercultural en México son producto de las luchas permanentes que han emprendido los grupos indígenas. Stavenhagen (1995) reconoce que los indios han encabezado movimientos en defensa y recuperación de las tierras de las que han sido desplazados, y por el reconocimiento de las lenguas indias y su uso, la adaptación del sistema educativo a las necesidades culturales del grupo étnico indígena y el control de la comunidad sobre las escuelas, como medida para contrarrestar el racismo de que son objeto, y reafirmar el derecho a la participación política, a la autodeterminación política, entre otros.

Vargas (2005), por su parte, sostiene que desde los años sesenta hay una correlación entre la mayor atención a las demandas de los pueblos y la movilización cívica social inicial por las cuestiones étnicas nacionales. La estrategia de estos movimientos de campesinos indígenas incorpora otros componentes en la lucha: la educación bilingüe intercultural, la reflexión contra la estructura del Estado y análisis del sistema político. La lucha por el reconocimiento de los derechos indígenas es uno de los más importantes movimientos sociales en México, es un fenómeno global, pues en todo el mundo existen las movilizaciones de grupos indígenas que buscan ser reconocidos como diferentes y con derechos a mejores condiciones de vida y a la participación política, jurídica y económica que les permita dejar de ser observadores y depositarios de las desgracias que las decisiones de otros han provocado. Esta lucha ha surgido por la conciencia de opresión y exclusión compartida por diversos grupos, que en su mayoría no se conocen entre sí, pero saben de su existencia y han aprovechado los medios de comunicación e información para construir vínculos y mantenerse en actividad, comunicándose.

Si bien es cierto que uno de los logros y conquistas de estos movimientos indígenas es el derecho a la educación pública, hace falta que se concretice cabalmente un servicio educativo que atienda la diversidad cultural y responda y garantice a todos los miembros de los pueblos indios adquirir una formación escolarizada en todos los niveles, con equidad al resto de la sociedad nacional, con planes y programas de estudio que integren la historia propia, sus conocimientos y técnicas, sus sistemas de valores, sus aspiraciones 
sociales, económicas y culturales. Desde la versión oficial, el Programa de Desarrollo Educativo 1995-2000, asume el compromiso de promover para las poblaciones originarias el desarrollo de actitudes de tolerancia y respeto a las diferencias.

En este sentido, hablar de interculturalidad es reconocer las diferentes identidades y procesos culturales diversos en el marco de sociedades complejas e interdependientes. Es entender que la diversidad cultural es más que un agregado de grupos diferentes aislados que comparten un territorio, y más bien asumirlos como grupos que se mantienen en contacto e interacción permanente, incluso grupos sociales que internamente presentan características, necesidades y condiciones diferentes. De tal manera, la educación debe responder con propuestas y acciones atendiendo la diversidad cultural a partir de análisis globales de las dinámicas sociales y su repercusión en grupos tradicionalmente desprotegidos y excluidos de esas dinámicas económicas y políticas.

Las formas de atención educativa a las poblaciones indígenas en México han pasado por muchos momentos, definidas por la política educativa, las intencionalidades de quienes ocupan el poder, los reacomodos de los personajes en las instituciones educativas, las demandas y movimientos de la población civil y los acuerdos de las instancias normativas y organismos mundiales; sin embargo, todas ellas tienen el mismo común denominador de integrar a las comunidades originarias a la sociedad hegemónica occidentalizada. En la época de la colonia, aparece como una estrategia para domesticar a los "nativos" el proceso de castellanización y evangelización. Su tarea era convertir al aborigen, al "animaloide" en un ser racional con quien los españoles se pudieran comunicar y entender. Igual suerte tuvieron los indígenas en las épocas posindependentista y porfirista, caracterizadas por la explotación y marginación de los pobres, monolingües autóctonos, campesinos en su gran mayoría pertenecientes a grupos indios.
Después de la revolución mexicana y recién creada la Secretaría de Educación Pública (SEP) con José Vasconcelos a la cabeza, se crea el Departamento de Educación y Cultura Indígena, que tiene como propósito construir una nación única y homogénea. En este propósito, se encuentra latente la idea de que México es diverso y que la educación es el mecanismo de integración a las diferentes poblaciones de la nación. Desde las iniciativas gubernamentales, el esfuerzo ha sido sistemático de encontrar un mecanismo a través de la educación para colonizar nuevamente a los indígenas.

Cerda (2007) hace un análisis de las políticas gubernamentales en torno a la atención a la educación intercultural. Muestra que desde las décadas posteriores a la revolución mexicana y hasta la actualidad, las políticas gubernamentales se han caracterizado por la buena voluntad para atender las poblaciones indígenas, pero están lejos de concretar los fundamentos de su origen y contrarrestar la hegemonía de la cultura dominante. Sostiene que:
Las actuales iniciativas gubernamentales en el campo de la educación intercultural, si bien han retomado una demanda histórica de los pueblos indígenas, la han vaciado de su potencial de transformación, sobre todo en el campo del reconocimiento político. De esta manera se han refuncionalizado a partir de una perspectiva reduccionista de sus implicaciones, lo cual significa dar continuidad a la postura indigenista que se gestara durante las décadas posteriores a la conclusión de la revolución mexicana (Cerda, 2007: 98).

La educación intercultural hoy en día se encuentra en una encrucijada entre la acción gubernamental y las propuestas críticas de teóricos, investigadores, luchadores sociales y amplios movimientos indígenas. Desde la postura oficial se aboga por que los niños indígenas de poblaciones en condiciones de vulnerabilidad y marginación social, política y económica se integren a la sociedad hegemónica 
occidentalizada a través de la incorporación de la lengua castellana que les permita el acceso a los conocimientos universales de la ciencia y la cultura global. Defiende que la única manera de salir de las condiciones en que se encuentran es a través de la educación formal institucionalizada. La postura crítica de la interculturalidad sostiene que la educación por sí misma no es suficiente para poder mejorar las condiciones de vida de estas poblaciones, sino más bien cuestiona las razones políticas, económicas y de poder social que han hecho que los indígenas estén en situaciones de vulnerabilidad y de exclusión social. Sostiene que sólo modificando estas condiciones de vida es posible acceder a una educación de calidad y pertinencia (Díaz y Alonso, 2004).

La educación intercultural no sólo es un servicio que se ofrece desde las instancias gubernamentales, es también una postura teórica, política y pedagógica de atención educativa dirigida a poblaciones históricamente marginadas, que cuestiona el status quo de la educación universal, homogénea y homogenizante y se dirige a cuestionar las condiciones sociales que generan desigualdades educativas.

\section{La castellanización como práctica pedagógica}

La perspectiva de la educación intercultural hace énfasis en el papel de la interacción social y la comunicación en el proceso educativo, de tal manera que la lengua materna constituye el sustento del proceso para favorecer la articulación y complementariedad entre creencias, saberes y conocimientos locales, con los regionales y globales, de modo que contribuyan a un pluralismo incluyente y se fomente el respeto y el diálogo entre los diferentes. Su importancia es crucial para promover la igualdad de oportunidades y de derechos para un sector de la población altamente marginado y en condiciones de pobreza extrema. Se insiste en la recuperación de la lengua indígena como un recurso poderoso en el aula que favorece el acto pedagógico y didáctico, pues las lenguas maternas de los niños son el punto de partida para la construcción y reconstrucción del conocimiento, además de que son un factor fundamental que favorece la comunicación dialógica y horizontal para la negociación de significados y significantes de los contenidos escolares y las relaciones sociales.

En este sentido, es necesario revisar las prácticas concretas de los profesores en contextos específicos, para estar en condiciones de evaluar las propuestas y objetivos de la educación intercultural. Para ello, se reúnen entrevistas con profesores y datos de observaciones en el aula, con el fin de mostrar las formas de castellanizar y negar la lengua materna de los alumnos.

En entrevista con un profesor, cuando se le interroga sobre sus experiencias con niños indígenas menciona que tiene:

...mucha experiencia en cuanto a los niños ieh?... hay niños que se les dificulta hablar la lengua castellana, pero el tzotzil, la lengua esa, se expresan como que sin tapujos. El chamaco se expresa, y este... uno le dice "icállate!", y uno no sabe de qué está hablando; puede que esté hablando de temas, y uno piensa que están diciendo otras cosas, platicando de otras cosas y no: están hablando del tema nada más que en su lengua, y eso hay que tener mucho cuidado... Nosotros como docentes tenemos que tener mucho cuidado en eso de... acercarse, "a ver, ven, platica", y si veo que es en base al tema pues ya... y casi en la clase esa es su forma de comunicación (E/Arqui, abril, 2008, ocp).

La presencia de la lengua, más que un poderoso recurso pedagógico y didáctico es un "estorbo" para los maestros y un pretexto para promover formas de dominación y ejercicio del poder (Belgich, 2005: 47).

Los elementos de significación que el niño utiliza como recurso de su saber cotidiano, son mayoritariamente excluidos por lainstitución. Tantopor la conformación 
de un tiempo y un espacio que ordena un modo de disciplinar el cuerpo, como también un modo de sentir los afectos propios y de los otros. Se conforma un cuerpo que se adecua a los afectos de la institucionalización (Belgich, 2005: 47).

En la escuela, y propiamente en la clase, se debe hablar sobre los contenidos escolares, formular las dudas y hacer comentarios en la "lengua legítima", que es el castellano. Lo que dicen los alumnos en su lengua materna, es leído por el maestro como desacato, desatención o desinterés que es necesario corregir. "La escuela, donde prima un orden de jerarquías de 'culturas superiores' y 'culturas inferiores', exige el cambio de los modos de decir, que en realidad responden al dialecto materno" (Belgich, 2005: 46). La identidad lingüística que los niños han recibido de sus padres y de generaciones anteriores, en lugar de afianzarla, es rechazada por los profesores y la escuela. Los procesos de identidad que al niño le daban seguridad sucumben ante las discriminaciones y desvalorización que provienen del exterior, las que se van afianzando en la subjetividad de los individuos y van construyendo imágenes deterioradas del contexto inmediato y de las relaciones sociales con el grupo de pertenencia: se crea desconfianza de lo que los otros cercanos le han dicho que es o no es. Las certidumbres que hasta ese momento daban sentido a la existencia de un niño proveniente de un medio indígena, así como su relación con los otros y con la naturaleza, se desmoronan por el reemplazo obligado de una lengua altamente valorizada. Las desvalorizaciones de su lengua materna que el niño recibe del exterior, van formando marcas o huellas mnémicas ${ }^{1}$ que más tarde se convierten en una autodesvalorización de la propia cultura.

Para Belgich (2005), una de las variables que mayor influencia tiene en el fracaso escolar de los niños de origen étnico, cultural o social distinto al de la media escolar, es precisamente la autodesvalorización de su propia lengua y cultura. Esta autodesvalorización se enlaza fuertemente a las rupturas de los lazos del sujeto con los valores transmitidos por los padres, en los procesos de socialización primaria.

El discurso del profesor muestra una visión que se identifica con las ideas pedagógicas homogenizadoras que han dominado en la sociedad moderna: indica que los sujetos socioculturales dejen en la puerta su "ropa" —obviamente por su bien-, para ponerse otra que le promete un futuro mejor; de esta manera, en la escuela predomina el sujeto pedagógico ${ }^{2}$ sobre los sujetos sociales, figura que los suprime y lucha por imponer su hegemonía a través de la supervisión y dominación del cuerpo, la vestimenta, el lenguaje y los comportamientos. Este mecanismo de anulación y negación de identidades sociales y culturales de los alumnos, por su condición indígena, es un proyecto que funciona con base en inclusiones y exclusiones, mediante un proceso de homogenización que niega reconocimiento del otro en su diferencia.

Esta situación no es sencilla para el alumno: se le calla la voz, la palabra que intenta decir algo, para cuestionarlo de otro modo y con otras herramientas culturales, las mismas que utilizaron los conquistadores para "humanizar al salvaje", para "adoctrinarlo", con aquello que los profesores dicen que debe ser lo correcto: el idioma castellano. Todo aquello que el niño indígena ha aprendido de su grupo cultural, de sus primeras relaciones con el mundo, es anulado por este acto del maestro; ya no sirve, no importa.

Para Lenkersdorf (2002), las lenguas son más que meros mecanismos de comunicación: sirven para nombrar la realidad y para nombrarnos a nosotros mismos, son una manifestación de las percepciones que se tiene de la realidad, de la vida y de los otros, además de ser las vías para comprender los contenidos de otras culturas, porque éstas incluyen sus percepciones y las expresan. En este sentido, es pertinente sostener que en la práctica pedagógica que realizan los profesores se lleva a cabo un "lexicidio" del lenguaje indígena, una matanza a los códigos lingüísticos y a la palabra, por medio de una violencia simbólica ${ }^{3}$ que se ejerce 
sobre el alumno de manera arbitraria con el propósito de anularlo. Cuando se anula la posibilidad de que el alumno hable en su propia lengua en el aula, no se violenta únicamente al individuo como tal, sino que se anula a todo el grupo del que es representante, se mata una cultura y una forma de ser y vivir en el mundo. Sin embargo, es una muerte lenta y silenciosa, no deja rastros que perseguir, no hay culpables, se le tolera y se le estimula.

De esta manera, se asume la conveniencia de que los alumnos se liberen de las identificaciones étnicas y de las apropiaciones culturales nativas que les impiden participar plenamente de una "cultura legítima", dejando de lado los contenidos y representaciones de la cultura materna, insistiendo así en que si las escuelas favorecen que los alumnos mantengan esas identificaciones, se retrasa el crecimiento académico del estudiante y se contribuye al retraso de los grupos étnicos. El objetivo de la escuela es, entonces, liberar a los estudiantes de sus características étnicas para permitirles adquirir los valores y conductas de la cultura dominante. Para Bourdieu (1998) la escuela es la principal instancia de legitimación de lo arbitrario cultural, que contribuye a la reproducción de la estructura de distribución de capital cultural entre las clases y, en ese proceso, a la reproducción de las relaciones de dominación existentes.

Llama la atención la concepción tan limitada con que se mira al alumno indígena y la idea predominante de los profesores que sostiene que el individuo es responsable de su propio fracaso. El fracaso se pondera a partir de la imposibilidad que tiene el alumno indígena de adecuarse a la norma construida por el poder de una cultura dominante. Para Kaplan (2005), esta concepción con que se mira la educación reinaugura un tipo de darwinismo social, haciendo que cada sujeto renuncie a su patrimonio cultural y adopte el del opresor para que pueda acceder a los puntajes (calificaciones, comportamientos, actitudes) que el sistema educativo impone para acreditar un grado escolar.
En este sentido, Giroux (2003) sostiene que los estudiantes de las clases trabajadoras, las mujeres, los negros y otros, necesitan afirmar sus propias historias por medio de su propia lengua, de un conjunto de relaciones sociales y de un cuerpo de conocimientos que críticamente reconstruyen y dignifican las experiencias culturales, que conforman el tejido, textura e historia de sus vidas cotidianas. Sin embargo, los acontecimientos en la clase y los discursos del profesor muestran la imposibilidad que tienen los alumnos de expresar sus expectativas, dudas o conocimientos en su propia lengua.

En entrevista el profesor menciona:

...pero si ha sido en algunos casos no ha sido tan difícil, porque al menos en mi carrera me he topado con niños hablantes de español, y que sí hablan una lengua indígena y pero que la hablan nada más para comunicarse con su familia y dentro del aula lo hablan muy poco. Aquí por ejemplo hablan tzotzil y español, pero aquí nos comunicamos en español (E/Far, abril, 2008, ocp).

La acción pedagógica que niega la lengua materna de los alumnos opera como mecanismo de opresión, ejercicio de imposición. Desde estos actos concretos que dan cuenta los profesores, icómo articular los diferentes saberes, perspectivas, formas de entender el mundo y formas concretas de relación social que favorezcan una práctica educativa intercultural? ¿Cómo promover el diálogo permanente entre los actores concretos del acto pedagógico? Para Stenhouse "la divergencia en el código lingüístico habitual constituye un síntoma de una separación cultural mucho más profunda en valoraciones y comprensiones, es decir, en la percepción de la realidad" (Stenhouse, 1991: 62). En esta divergencia entre la lengua materna que dominan los alumnos y el castellano del profesor, se diluye la posibilidad de encontrar puntos de coincidencia para establecer un diálogo intercultural, configurándose lo que León Trujillo (2008) llama "mundos en tensión". 
Para Belgich (2005), la escuela es una máquina semiótica, cuyo funcionamiento se basa en construir un modo de dar significado a los enunciados, hechos y cosas de la realidad. Este modo de significar es propio de un régimen donde se instaura una palabra legítima que representa la parte del tejido de significaciones que se revelan como dominantes dentro del imaginario social. Las significaciones que poseen mayor eficacia social son aquellas que pertenecen a la particular manera de funcionar del capitalismo, la globalización y el neoliberalismo de este siglo.

En esta situación los alumnos tienen que asumir valores, representaciones y percepciones de la realidad propios de un grupo cultural ajeno a ellos, así como patrones lingüísticos que carecen de importancia en su vida cotidiana. En estas condiciones, el acto pedagógico está destinado al ejercicio del poder de los profesores sobre los alumnos, operando como un poder que domina, de tal manera que "aquí [(en la comunidad)], por ejemplo, hablan tzotzil y español, pero aquí [(en el salón de clases)], nos comunicamos en español". Para el profesor es hasta cierto punto "natural" que en el salón se comuniquen en español; las prácticas pedagógicas cotidianas se hacen en el idioma dominante, no necesitan ser de otra manera. Para Gentili (2001) lo normal se vuelve cotidiano y la visibilidad de lo cotidiano se desvanece como producto de su tendencial naturalización.

Hablar en castellano en el salón de clases es una forma de ejercitar y disciplinar el cuerpo y el espíritu para incorporar lo que es valioso y dejar de lado aquello que estorba. Es la manifestación de un poder minúsculo y legitimado para la construcción de aptitudes y habilidades que posibilite la entrada del sujeto a un grupo cultural que ofrece mayores oportunidades de desarrollo y de bienestar a costa de dejar de ser lo que culturalmente se es. Para Foucault (1993) la disciplina implica un vínculo entre la obediencia y la utilidad. En la medida en que uno obedece, tiene más posibilidad de hacer lo útil, lo necesario y a la inversa: hacer lo útil y necesario implica obediencia. De este modo, en esta obediencia opera un mecanismo de poder para fortalecer una lengua y disminuir otra.Foucault nos dice:

La disciplina aumenta las fuerzas del cuerpo (en términos económicos de utilidad) y disminuye esas mismas fuerzas (en términos políticos de obediencia). Disocia el poder del cuerpo; de una parte, hace de este poder una aptitud, una capacidad que trata de aumentar, y cambia por otra parte la energía, la potencia que de ello podría resultar a la que convierte en relación de sujeción estricta (Foucault, 1993: 142).

En este sentido, la designación del profesor “...pero aquí [(en el salón de clases)] nos comunicamos en español", es un mandato que exige obediencia y control sobre el cuerpo y los discursos de los niños, es provocar una colonización sobre la significación de la realidad y la forma de nombrarla, es una dominación acrecentada sobre una forma de ser en el mundo que se construye y se vive como natural.

Reconociendo que los procesos interculturales deben conformarse por el encuentro y la apertura a las cosmovisiones, de otros modos de ser y estar, la lengua ofrece la posibilidad de objetivar estas percepciones para entrar en un proceso de diálogo en la comprensión y respeto del otro y de negociación que construya nuevas visiones del mundo y la realidad. Negar esto, es desconocer que el desarrollo del niño está siempre mediatizado por determinantes culturales que su realidad cotidiana tiene. El niño necesita nombrar esa realidad, misma que tiene un sentido culturalmente construido en el grupo al que pertenece, y que va adquiriendo en la convivencia social: “...el mundo de los niños está codificado por el lenguaje, mismo que representa la naturaleza transformada por la historia y por la cultura" (Gimeno \& Pérez, 2002: 218).

Desde esta perspectiva podemos decir que el quehacer del maestro se produce fuera del contexto 
cultural y de las características concretas de los alumnos. La significatividad de los contenidos escolares se construye cada vez que el niño es capaz de establecer relaciones sustantivas y no arbitrarias entre lo que se intenta que aprenda y lo que conoce. De tal forma que la riqueza de los aprendizajes de los niños se dan en la medida de las relaciones que se establecen entre los contenidos escolares y las vivencias cotidianas de los niños. ¿Qué significatividad puede encontrar el niño a los contenidos escolares si estos se alejan de sus conocimientos previos?

Los profesores reconocen la importancia de la lengua, saben que es una condición "natural" de la que no se puede escapar. Los niños llegan hablando en tzotzil, pero en la medida en que la escolarización domina su mundo simbólico, sus cuerpos y sus comportamientos, calla también la palabra indígena, y en esta acción se reducen las posibilidades para el aprendizaje significativo y guiado que propone la educación intercultural. La recuperación de los aprendizajes previos que se han construido en el intercambio cotidiano del niño con el adulto en los espacios comunitarios, se considera un "estorbo" a la hora de enseñar los contenidos escolares.

...la lengua es importante... importante tanto como para que haya calificación tanto del maestro como del alumno, el maestro con el padre de familia, y es de mucha importancia porque es la estrategia que se puede utilizar para el conocimiento, para dar conocimiento a los niños. Yo lo pienso como una estrategia, pero en los primeros grados sí es funcional la lengua porque ahí los niños manejan sólo la lengua materna, la lengua tzotzil; ya los que están en segundo, que están en segundo o más grandes, pues ya le entienden al español, le entienden, ya los grados posteriores ya... ya se les puede dar el tema en español y ellos también ya pueden empezar a dominar la lengua, ya el niño es bilingüe. Y en primero es importante que el maestro hable la lengua materna del niño porque el niño aún no tiene el dominio del español y con base en lo que es el aprendizaje del español y... va a poder... va a poder socializarse, va a poder platicar con el maestro (E/Arqui, abril, 2008, ocp.).

La escuela aparece entonces como un mecanismo legitimado socialmente para la integración de los niños a la cultura nacional hegemónica, como un espacio institucionalizado para ejercer el poder desde el Estado, que de manera acrítica y sin reflexiones concretiza el maestro. Existe una preocupación de los profesores por asignar calificaciones (numéricas) al desempeño de los alumnos, necesitan dar respuestas sobre su trabajo y su rendimiento, lo que se traduce en aquello que Foucault (1993) llama "microeconomía de las actividades escolares", consistente en asignar un valor a cada una de estas actividades.

En el discurso del maestro sobre que “...la lengua es importante... importante tanto como para que haya calificación tanto del maestro como del alumno...", se busca encontrar un vínculo comunicativo que le permita señalar las desviaciones, jerarquizar las cualidades, las competencias y las aptitudes, los niveles de responsabilidad y compromiso de los alumnos y, desde luego, castigar y recompensar. Aparece también, como si fuera un riesgo de la no castellanización, el no poder mostrar las desviaciones de los alumnos, y no tener la posibilidad de corregirlos para que logren el "bien" a través de los conocimientos valiosos y verdaderos.

Por otro lado, decir que “... en primero [(primer grado)] es importante que el maestro hable la lengua materna del niño porque el niño aún no tiene el dominio del español y con base en lo que es el aprendizaje del español y... va poder... va poder socializarse, va poder platicar con el maestro...", muestra que la incorporación del español al lenguaje de los niños viene a ocupar el lugar de una obligación, misma que aparece en las primeras experiencias del alumno en la escuela para que, una vez introyectada, pase a formar parte de una condición "natural" del proceso educativo. 
Por otro lado, el dominio del idioma español posibilita hacer las tareas, participar en clases, leer los textos que están en ese idioma, con lo que los alumnos van a dejar de ser "flojos" para incorporarse al trabajo que exige el aprendizaje escolar y dejar lo "incivilizado" que caracteriza a los grupos indígenas. Esto sostiene que la única salida posible para ellos es la asunción de la lógica del mérito, consistente en que los más "inteligentes", "capaces", "dedicados" e "interesados" puedan sobresalir y estar en condiciones de insertarse al mercado laboral y a las oportunidades que da la ciudadanía mestiza.

Si bien es cierto que la educación intercultural se resiste a la epistemología científica disciplinaria de la razón occidental, en los escenarios concretos de las escuelas estudiadas, las diferencias de los alumnos respecto al maestro se vuelven desigualdades y oposiciones, de tal manera que los niños provenientes de contextos excluidos, deben acostumbrarse al ejercicio del poder de manera silenciosa para acceder a los "requisitos" y los conocimientos de una cultura valiosa y prometedora.

La imposición de una cultura en el aula conduce al desarrollo de una estructura semántica enciclopedista que no enriquece en nada los esquemas que los alumnos utilizan para interactuar y resolver problemas en su mundo sociocultural. Los primeros años de escolarización son los decisivos para la incorporación de la lengua extranjera (el castellano), pues a los de primer y segundo grado se les permite hablar la lengua indígena en el salón de clases, pero en la medida en que avanza en los grados escolares se incorpora el español y se pierde la lengua materna como el elemento principal de interacción y comunicación para promover los aprendizajes.

La presencia de la lengua materna en el salón de clases es considerada un distractor para el maestro, un peligro para su tarea, de allí la necesidad de incorporar el español para que el alumno "platique" con el mentor. La frase que circuló en un curso de actualización docente para promover la lectura: "si no sabe español, no va a poder aprender", muestra con claridad el posicionamiento compartido de los profesores frente al problema de la lengua materna.

En una observación realizada en una sesión donde el Asesor Técnico Pedagógico ${ }^{4}$ (ATP) trabajaba el tema de las competencias comunicativas, se dijo lo siguiente:
ATP - Es importante que ustedes desarrollen las competencias comunicativas. ¿Saben qué es una competencia?
Coro de niños - iNooooooo!

ATP - A ver niños... ¿Qué otras cosas hacen aparte de la tarea?

Niños - (silencio).

ATP - Porque no siempre van a estar haciendo la tarea... ¿Qué más hacen?

Un niño - Leer (voz temerosa)

ATP - Leer, muy bien, leer es una competencia comunicativa, porque a través de la lectura te comunicas.

Otros niños -platicamos, jugamos, reímos.

ATP - Muy bien, platican, y cuando platican comunican algo.

ATP - Cuando no pueden hablar cómo se comunican. Unos niños -Con señas, con letras, escribiendo.

ATP - Muy bien, a través de la escritura ustedes se pueden comunicar.

La clase con el ATP transcurre de la misma manera, en un preguntar por su parte y un responder de los alumnos, hasta que los niños dijeron que escuchar, hablar, escribir y leer son las competencias comunicativas (Obs./ $5^{\circ}$. y 6․ Grado, 22 de enero, 2008, ocp).

Dos situaciones se muestran con estos datos: la primera tiene que ver con la forma en que se enseñan las competencias comunicativas. Sin tratar de profundizar sobre este modelo, que no es el objetivo del artículo, es necesario resaltar que el enfoque por competencias implica una postura curricular a modo que se traduzca en un conjunto de tareas planeadas y organizadas para 
que el alumno sea capaz de hacer, entender, explicar, demostrar y evaluar lo que sabe. Para que una propuesta curricular esté basada en el modelo por competencias debe incluir dentro de otros elementos un conjunto de tareas que permitan que ocurran varias acciones intencionales simultáneamente, además de tomar en cuenta el contexto en el cual tiene lugar la acción. El modelo curricular por competencias reconoce que es posible ser competente de diversas maneras, lo cual exige juicios basados en las evidencias. En este sentido, el trabajo del ATP se aleja sustancialmente de este modelo; más bien es un ejercicio de inculcación de una lengua dominante y la clausura de otra que se considera inferior. A partir de un contexto particular y reconociendo que la comunicación es el eje central del acto pedagógico y el elemento crucial para la convivencia humana, la habilidad comunicativa debe proponerse de forma transversal dentro de los contenidos, estrategias y actividades de aprendizaje. Si la educación intercultural intenta crear un aula escolar como un contexto de comunicación y un espacio de conocimiento compartido, implica necesariamente comprometerse por construir verdaderos procesos de negociación abiertos y permanentes a través de una relación horizontal y dialógica para la comprensión común, enriquecida constantemente con las aportaciones de los sujetos que participan y dan sentido a la escuela, reconociendo a cada uno sus posibilidades y competencias.

La segunda situación es la negación de la lengua materna de los alumnos como una posibilidad real, necesaria e ineludible para la comunicación, el intercambio social y para la enseñanza y el aprendizaje del mundo. El Programa Nacional Educativo 2000-2006 retoma entre sus prioridades la de asegurar la equidad y calidad de la oferta educativa y propone la construcción de una educación pertinente para la población indígena, que respete las diferentes formas de expresión cultural y fortalezca la capacidad lingüística de los habitantes originarios, a través del rescate y promoción de las lenguas autóctonas, considerando y dando respuesta a las necesidades derivadas de la diversidad cultural.

En la práctica pedagógica concreta que hemos examinado se niega lo que es el hablante indígena, su lengua, que forma parte de su ser, de su ropaje cultural. La tarea de los profesores es seguir el programa indicado en el libro de texto con la intención de cubrir el temario, con su respectivo miedo a la pérdida de tiempo; de allí que cierren las puertas al hecho de mirar, valorar y promover la lengua materna de sus alumnos.

Reconocemos explícitamente que el discurso sobre la igualdad, los derechos y la equidad social en que se construye la escuela y la sociedad moderna son meros artificios discursivos donde no hay lugar para todos, donde los beneficios son sólo para algunos. La tarea de una escuela democrática como lo postula la educación intercultural, debe contribuir a volver visible lo que el discurso hegemónico ha empañado, de tal manera que las prácticas y miradas normalizadoras y segregadoras queden a la vista, para favorecer la construcción de nuevas realidades en los contextos indígenas:

No es posible solicitar la interculturalidad desde la exclusión social o pedir una convivencia tranquila desde la continua estereotipación de la diversidad. La única educación intercultural posible es aquella que no renuncia a su pluralidad en nombre de una cultura (Marí, 2007: 107).

\section{Conclusiones}

El trabajo es una reflexión crítica de la práctica pedagógica concreta de dos escuelas interculturales bilingües de educación primaria de comunidades de los municipios Ocozocoautla y Berriozábal del estado de Chiapas. Mostró que la educación en general y la intercultural en particular se construyen a través de discursos y esperanzas no alcanzadas.

Toda propuesta educativa tiene implícita o explícitamente una concepción de hombre y sociedad 
a partir de los intereses de los grupos hegemónicos. La educación intercultural, como propuesta pedagógica, se sostiene a partir de los postulados de una sociedad liberal que pugna por el individualismo, la competencia con otros y la distribución desigual de los recursos y oportunidades reales. En las prácticas escolares concretas observadas, la tarea central es integrar al alumno indígena a la cultura hegemónica a través del ejercicio del poder y dominación, ya sea negando su lengua materna, modelando los cuerpos, castigando las formas de resistencia y desvalorando la identidad propia.

La propuesta curricular homogénea que presenta la SEP para la educación primaria, aunada a las carencias materiales y simbólicas de las comunidades y los centros escolares, el desconocimiento de la lengua local para la práctica pedagógica, los discursos y prácticas de los profesores que encarnan la violencia real y simbólica, así como las estrategias de sobrevivencia de los alumnos en las escuelas, hacen que converjan en un mismo espacio tanto el poder estructural como el poder microsocial.

Para resolver los problemas pedagógicos en las escuelas bilingües se han contratado profesores indígenas que hablan la lengua de los alumnos. Sin embargo, hablar la lengua de los alumnos, sin valorarla, no es suficiente para darle mejor sentido y significatividad al acto pedagógico.

Los procesos de contratación de profesores deben definirse a partir de un perfil que tome en cuenta otras características (formación pedagógica, interés por los grupos indígenas, expectativas de la educación) y no sólo la lengua indígena. Los discursos institucionales sobre la educación intercultural no articulan la educación, la política y la economía para resolver los problemas de exclusión y marginación social donde se insertan las escuelas de este tipo. La atención educativa a la diversidad cultural se encuentra desarticulada entre las políticas educativas, los acuerdos de organismos educativos y las propuestas legislativas, con las prácticas pedagógicas concretas en los contextos escolares estudiados, por lo que es imprescindible repensar la educación y la escuela intercultural desde el ámbito político y económico.

Los datos recuperados en la investigación se pueden amalgamar con los resultados de otros compañeros, como los de León y Martínez (2008), Bermúdez (2010), Gómez (2004), que han estudiado contextos educativos en Chiapas y que comparten las mismas preocupaciones, surgidas de datos muy similares, para promover propuestas de reformas a la política educativa, a los procesos de contratación, capacitación, adecuaciones curriculares, trabajos con las comunidades, que permitan ofrecer mejores condiciones de vida y de formación académica a las poblaciones históricamente marginadas del estado. Por otro lado, sostengo la convicción de que lo compartido será enriquecido por los interesados e investigadores en la temática, a fin de impactar sobre la actividad docente o el proceso educativo institucionalizado en los contextos estudiados.

\section{Notas}

' Término utilizado por Freud, a lo largo de toda su obra, para designar la forma en que se inscriben los acontecimientos en la memoria. Las huellas mnémicas se depositan, según Freud, en diferentes sistemas; persisten de un modo permanente, pero sólo son reactivadas una vez catectizadas (o que cierta energía psíquica se halle unida a una representación o grupo de representaciones) (Laplanche, 1993: 177).

${ }^{2}$ Se hace referencia al sujeto escolarizado que debe someterse sin resistencia a los mandatos de la institución escolar para que pueda acceder a los contenidos científicos que la escuela ofrece, desconociendo las propias necesidades, intereses, motivaciones y deseos del contexto social y cultural de procedencia.

${ }^{3}$ Todo poder de violencia simbólica, o sea todo poder que logra imponer significaciones e imponerlas como 
legítimas disimulando las relaciones de fuerza en que se funda su propia fuerza, añade su fuerza propia, es decir propiamente simbólica, a esas relaciones de fuerza (Bourdieu, 1998: 44).

${ }^{4}$ Los ATP son los responsables de asesorar y acompañar a los profesores que están frente a grupo. Cada uno de ellos tiene varias escuelas bajo su responsabilidad; hacen visitas a los centros escolares para apoyar en las dificultades de proceso de enseñanza y aprendizaje y ofrecen cursos y actividades de asesoramiento.

\section{Bibliografía}

Aguado, T. (2003), Pedagogía intercultural, México: McGrawHill.

Belgich, H. (2005), Escuela violencia y niñez. Nuevos modos de convivir, Argentina: Homo Sapiens.

Bermúdez, F. M. (2010), Del Campo a la Ciudad: los Migrantes Indígenas en San Cristóbal de Las Casas. Análisis del Proceso de Escolarización: de la Educación Primaria Bilingüe Intercultural a la Educación Superior, Tesis para la obtención del título de Doctor en Pedagogía, México: Facultad de Filosofía y Letras, UNAM.

Bourdieu, P. \& Passeron J-C. (1998), La reproducción. Elementos para una teoría del sistema de enseñanza, Tercera edición, México: Fontamara.

Cerda García, A. (2007), "Multiculturalidad y educación intercultural entre el neoindigenismo y la autonomía", en Andamios: revista de investigación social, núm. 6, vol. 3, México: UNAM, pp. 7-135.

Díaz, R. y Alonso, G. (2004), Construcción de espacios interculturales, Argentina: Miño y Dávila.

Dietz, G. (2009), "Los Actores Indígenas ante la "Interculturación" de la Educación Superior en México: iempoderamiento o neoindigenismo?", en Revista Latinoamericana de Educación Inclusiva, núm. 3, vol. 2, (en línea) http://www.rinace.net/rlei/numeros/ vol3-num2/art4.pdf. [consultado: 12 de agosto de 2010], pp. 55-75.
Foucault, M. (1993), Vigilar y castigar, vigésima primera edición, México: Siglo XXI.

Gentili, P. (2001), "Un zapato perdido: o cuando las miradas saben mirar", en Revista Cuadernos de pedagogía, núm. 308, pp. 24-29.

Gimeno, Sacristán, J. \& Á. Pérez Gómez (2002), Comprender y transforma la enseñanza, Madrid: Morata.

Giroux, H. (2003), La escuela y la lucha por la ciudadanía, México: Siglo XXI.

Gómez Lara H. (2004), "Educación e identidades de género, clase y etnia en San Andrés Sacamch'en (Larráinzar)", en Olivera Bustamante, M. (Coord.) (pp. 170-221), De sumisiones, cambios y rebeldías mujeres indígenas de Chiapas, vol. I, México: UNICACH, CONACYT, UNACH.

Kaplan C. (2005), "Desigualdad, fracaso, exclusión: ¿Cuestión de genes o de oportunidades?", en Llomovatte, S. \& C. Kaplan (coords.), Desigualdad educativa. La naturaleza como pretexto, México: Noveduc, pp. 75-98.

Laplanche, J. \& Jean-Bertrand P. (1993), Diccionario de psicoanálisis, México: Paidós.

Lenkersdorf, C. (2002), Otra lengua, otra cultura, otro derecho. El ejemplo de los mayas-tojolabales, (en línea) http:/www.bibliojuridica.org/libros/2/740/6. pdf, (consultado:20 de mayo 2010).

León Trujillo, A. (coord.) (2008), Diversidad cultural y escuela. Mundos en tensión, México: Universidad Pedagógica Nacional, Unidad 071.

Marí Ytarte, R. (2007), ¿Culturas contra ciudadanía? Modelos inestables en educación, España: Gedisa.

Secretaria de Educación Pública, Programa Nacional de Educación 2001-2006.

Stavehagen, R. (1995), "Democracia, modernización y cambio social en México", en México, el exilio bien temperado, México: Instituto de Investigaciones Interculturales Germano-Mexicanas, A.C., Instituto Goethe México, A.C., Secretaría de Cultura del Estado de Puebla \& UNAM. 
y la Ecología Política Indígena", (en línea) Revista Ra Ximhai, núm. 1, vol. 3, pp. 453-470. http://www.uaim. edu.mx/webraximhai/Ej-03articulosPDF/02\%20 mov\%20sociales.pdf, [consultado: agosto 18 de 2010]. 